\title{
Tunable Keratin Hydrogels for Controlled Erosion and Growth Factor Delivery
}

\author{
Trevor R. Ham ${ }^{1,2}$, Ryan T. Lee ${ }^{1}$, Sangheon Han ${ }^{1}$, Salma Haque ${ }^{1}$, Yael Vodovotz ${ }^{3}$, Junnan \\ $\mathrm{Gu}^{3}$, Luke R. Burnett ${ }^{4}$, Seth Tomblyn ${ }^{4}$, and Justin M. Saul ${ }^{1, *}$ \\ ${ }^{1}$ Department of Chemical, Paper and Biomedical Engineering, Miami University, 650 E. High \\ Street, Oxford, OH 45056, USA \\ ${ }^{2}$ Department of Biomedical Engineering, University of Akron, Auburn Science and Engineering \\ Center 275, West Tower, Akron, $\mathrm{OH} 44325$, USA \\ ${ }^{3}$ Department of Food Science and Technology, The Ohio State University, 2015 Fyffe Court, \\ Columbus, $\mathrm{OH} 43210$, USA \\ ${ }^{4}$ KeraNetics, LLC, 200 East First St. Box 4, Suite 102, Winston-Salem, NC 27101, USA
}

\begin{abstract}
Tunable erosion of polymeric materials is an important aspect of tissue engineering for reasons that include cell infiltration, controlled release of therapeutic agents, and ultimately to tissue healing. In general, the biological response to proteinaceous polymeric hydrogels is favorable (e.g., minimal inflammatory response). However, unlike synthetic polymers, achieving tunable erosion with natural materials is a challenge. Keratins are a class of intermediate filament proteins that can be obtained from several sources including human hair and have gained increasing levels of use in tissue engineering applications. An important characteristic of keratin proteins is the presence of a large number of cysteine residues. Two classes of keratins with different chemical properties can be obtained by varying the extraction techniques: (1) keratose by oxidative extraction and (2) kerateine by reductive extraction. Cysteine residues of keratose are "capped" by sulfonic acid and are unable to form covalent crosslinks upon hydration, whereas cysteine residues of kerateine remain as sulfhydryl groups and spontaneously form covalent disulfide crosslinks. Here, we describe a straightforward approach to fabricate keratin hydrogels with tunable rates of erosion by mixing keratose and kerateine. SEM imaging and mechanical testing of freeze-dried materials showed similar pore diameters and compressive moduli, respectively, for each keratosekerateine mixture formulation ( $\sim 1200 \mathrm{kPa}$ for freeze-dried materials and $\sim 1.5 \mathrm{kPa}$ for hydrogels). However, the elastic modulus ( $G^{\prime}$ ) determined by rheology varied in proportion with the keratosekerateine ratios, as did the rate of hydrogel erosion and the release rate of thiol from the hydrogels.
\end{abstract}

\footnotetext{
*Corresponding Author: Justin M. Saul, Ph.D., Department of Chemical, Paper and Biomedical Engineering, 650 East High Street, Engineering Building, Room 064L, Miami University, Oxford, OH 45056, (513) - 529 - 0769, office phone, sauljm@ MiamiOH.edu. ASSOCIATED CONTENT

Supplemental Figure 1. Porosity of each keratin mixture formulation as determined by mercury intrusion porosimetry on $10 \% \mathrm{w} / \mathrm{v}$ gels. Error bars indicate standard deviation and $\mathrm{n}=3 . *$ Indicates $\mathrm{P}<0.05$ between indicated groups.

Author Contributions

The manuscript was written through contributions of all authors. All authors have given approval to the final version of the manuscript.
} 
The variation in keratose-kerateine ratios also led to tunable control over release rates of recombinant human insulin-like growth factor 1.

\section{Keywords}

Tissue engineering; regenerative medicine; drug delivery; insulin-like growth factor 1; rheology; mechanical properties; degradation

\section{Introduction}

Polymeric materials are used extensively in tissue engineering or regenerative medicine (TERM) applications as they provide a mechanical support to cells that play a role in reparative functions. Polymers are also desirable in these applications due to their ability to achieve controlled delivery of therapeutic agents to promote desired cell/tissue functions. Unlike traditional implanted materials, polymeric materials in TERM applications are designed to erode over time, preferably at a rate inversely proportional to tissue healing (Figure 1A).

Synthetic polymers can be advantageous for tunable drug release due through control over chemical properties of the polymers. ${ }^{1,2}$ Factors that control the rates of hydrolytic degradation include the type of hydrolytic group (anhydrides vs polyesters), the length of carbon chains (polycaprolactone vs. polyvalerolactone), ${ }^{3}$ or the presence or absence of side chains (polyglycolic acid vs polylactic acid). Enzymes, ${ }^{4}$ light,,${ }^{5}$ ultrasound, ${ }^{6}$ temperature, ${ }^{7}$ and electrical current ${ }^{8}$ all have been used to achieve controlled erosion or drug delivery from synthetic polymeric biomaterials. However, synthetic materials tend to elicit more foreign body response (e.g., fibrous encapsulation) than natural polymers and generally require chemical modification with integrin-binding motifs or other cell adhesion molecules in order to promote favorable cell attachment, migration, and/or proliferation. $9,10,11,12,13$

Natural polymers used in TERM applications such as alginate, collagen, and fibrin generally have more favorable degradation products than synthetics. In addition, proteinaceous polymers commonly have amino acid sequences that promote cell adhesion. ${ }^{14,15}$ This ability of natural polymers to promote cell attachment may explain, in part, the commercial and medical success of synthetic bone graft materials, which predominately use a collagenbased matrix for delivery of recombinant human bone morphogenetic protein 2 (rhBMP-2).${ }^{16,17}$ It is also interesting that in the earliest successful clinical applications of tissue engineering, the material components were, in whole or in part, natural polymers. ${ }^{18,19,20}$ This increased biological utility often comes at the cost of greatly restricted material properties. Namely, natural polymers lack the tunability of synthetics in terms of erosion rate and controlled release of therapeutic agents. As such, natural proteinaceous polymers that can achieve more tunable rates of erosion without the use of external chemical crosslinkers would be advantageous.

Keratins are a class of natural polymers found in epithelial tissue as intermediate filament proteins (soft keratins). Keratins can also be readily obtained from various sources including feathers, hooves, wool and human hair (Figure 1B), the source of keratin described in this 
report. Keratins have been reported as stand-alone materials or with controlled release of therapeutic agents for TERM applications including those in nerve, ${ }^{15,21,22,23}$ muscle, ${ }^{24}$ skin, ${ }^{25,26,27}$ and bone. ${ }^{28,29,30}$ Keratins are known to promote attachment of various cell types including osteoblasts, ${ }^{31,32,33}$ fibroblasts, ${ }^{34}$ hepatocytes, ${ }^{35}$ and neural cells, ${ }^{15}$ though the mechanisms of attachment are not fully known in all cases. The inflammatory response to keratins is minimal. ${ }^{14}$ Further, humans are not known to express keratinase enzymes that specifically degrade keratins, providing the ability to resist in vivo degradation longer than other proteins such as collagen that are degraded by highly selective enzymes (e.g., collagenase).

A molecular feature of keratins that makes them of particular interest is that they inherently possess a relatively high number of cysteine residues, suggesting that materials derived from keratins could be formed with tunable degradation by exploiting levels of disulfide crosslinking. Chemically, the behavior of these cysteine residues depends on the method used to extract them e.g., from hair). Keratins can be extracted by oxidative methods (see Figure 1C) ${ }^{14,15}$ to yield a form of oxidized keratin known as keratose (KOS). In KOS, the cysteine sulfur atoms are in the form of sulfonic acid and therefore unable to form disulfide cross-links (Figure 1C). Keratins can also be extracted by reductive methods (see Figure 1C) $)^{36,37}$ to yield a form of reduced keratin known as kerateine (KTN). In KTN, the cysteine residues contain thiol groups and are able to form disulfide cross-links (Figure 1C). Therefore, hydrogels fabricated from KOS are known to erode relatively rapidly ${ }^{14}$ because they possess only physical entanglements and hydrophobic interactions but no covalent interactions. In contrast, hydrogels fabricated from KTN are more stable and erode more slowly ${ }^{36}$ due to the presence of physical entanglements and hydrophobic interactions as well as the presence of disulfide crosslinks.

These differences in the properties of KOS and KTN suggest a system that can be tuned through simple mixing of the two forms. We hypothesized that it would be possible to exploit the presence (or absence) of disulfide cross-links within keratin hydrogels by mixing KOS (with sulfonic acid group "caps" on cysteine) with KTN (with thiol groups capable of forming disulfide crosslinks) to achieve tunable rates of erosion and growth factor release based on the overall level of disulfide crosslinking. While there are several reports of chemical modifications to keratin proteins to modulate the rates of material erosion, ${ }^{33,}, 38$ the ability to tune the rate of erosion of keratin biomaterials by exploiting the disulfide crosslinks inherently present (or absent) in the different extracted forms of KOS and KTN has not been described in the literature. The ability to achieve such controlled erosion without complex chemical processing, in conjunction with its favorable biological properties, would provide a material with some of the advantages of both natural and synthetic materials.

In these studies, we describe an approach to fabricate keratin hydrogels from KOS-KTN mixtures (Figure 1D). We characterized the effects of disulfide crosslinking on key material properties including rheological properties of the hydrogels, compressive modulus, pore structure/porosity, and rates of erosion. We then characterized these materials for cell compatibility and controlled release of recombinant human insulin-like growth factor 1 (rhIGF-1) as a model growth factor. This approach represents a novel yet simple method 
through which control over the relevant material properties of keratin hydrogels can be achieved in order to provide additional flexibility for their use in TERM applications.

\section{Materials and Methods}

\subsection{Keratin Hydrogel and Scaffold Formation}

Keratose (KOS) and kerateine (KTN) were obtained as lyophilized, sterile (via 2 MRad gamma irradiation) powders from KeraNetics, LLC (Winston-Salem, NC) and used without further modification. $\operatorname{KOS}^{14}$ and $\mathrm{KTN}^{37}$ were extracted by proprietary methods similar to those previously reported. Mass percentage ratios of KOS:KTN investigated in these studies were 100:0, 70:30, 50:50, 30:70, and 0:100, where we use the nomenclature throughout this manuscript of KOS:KTN to represent the weight percentages of each component in the mixture.

Keratin hydrogels were formulated at 15\% (w/v) (with the exception of mercury porosimetry experiments, which were performed with $10 \%(\mathrm{w} / \mathrm{v})$ gels) with varying mass ratios of KOS:KTN. To form hydrogels, KOS and/or KTN powders were added to a tube in the appropriate amounts (Table 1) and vortexed vigorously to mix the powders. Water (containing rhIGF-1 in later experiments, see below) was then added to the powders to achieve $15 \% \mathrm{w} / \mathrm{v}$. The water-powder mixtures were mixed vigorously both manually (by spatula) and by vortex to achieve homogenous distribution. The resulting mixture was then loaded (manually) into a syringe and a desired volume of keratin was injected into an appropriate vessel (1.5 $\mathrm{mL}$ tube, $5 \mathrm{~mm}$ diameter mold, or $20 \mathrm{~mm}$ diameter mold) as described for each specific experiment, below. After adding to the appropriate vessel, keratin was allowed to gel at $37^{\circ} \mathrm{C}$ overnight. All keratin gels were formed using deionized water due to lack of gel forming capacity of KTN in phosphate buffered saline (PBS) or cell culture media. Keratin "scaffolds" used in compression tests were formed by freezing the keratin hydrogels at $-80^{\circ} \mathrm{C}$ and then freeze-drying the samples on a Labconco Freezone 4.5L lyophilizer (Kansas City, MO) for at least 48 hours.

\subsection{Rheology}

Keratin hydrogel formulations from Table 1 were formed in $20 \mathrm{~mm}$ diameter and $2 \mathrm{~mm}$ high templates and subjected to rheological testing on a TA Instruments HR-1 Discovery Rheometer (New Castle, DE) with standard steel parallel-plate, $20 \mathrm{~mm}$ diameter geometry as previously described. ${ }^{33}$

\subsection{Compression Testing of Keratin Scaffolds and Hydrogels}

We assessed the compressive mechanical properties of the keratin formulations both as lyophilized scaffolds and as hydrogels. Hydrogels were prepared as described in Section 2.1 and formed into $5 \mathrm{~mm}$ diameter by $5 \mathrm{~mm}$ high molds as previously described. ${ }^{33}$ The samples were allowed to gel overnight at $37^{\circ} \mathrm{C}$ before testing. For scaffolds, the hydrogels were frozen at $-80^{\circ} \mathrm{C}$ and then placed on a Labconco lyophilizer for at least 48 hours. Hydrogels or scaffolds were placed on a Bose Electroforce 3200 mechanical tester equipped with a 10 $\mathrm{N}$ load cell. Samples were then compressed at a rate of $2 \mathrm{~mm} / \mathrm{min}$ to $20 \%$ engineering strain. The resulting load-displacement data was converted to engineering stress vs. engineering 
strain plots and a least squares fit was applied to the linear region to determine the compressive (Young's) modulus. We note that samples (hydrogels or scaffolds) were not subjected to swelling prior to testing because the materials eroded and were also too soft to obtain good mechanical readings with the available $10 \mathrm{~N}$ load cell. Therefore, data are reported for unswelled materials.

\subsection{Scanning Electron Microscopy and Mercury Porosimetry}

Scanning electron microscopy (SEM) was used to visualize the pore architecture of the KOS:KTN keratin mixtures and determine any differences or lack of structures typical of gelled keratin materials as a result of the mixture fabrication approach. Keratin hydrogels were prepared at the various ratios described in Section 2.1 and loaded into a syringe. Approximately $400 \mu \mathrm{L}$ of the keratin in water was placed into a $1.5 \mathrm{~mL}$ tube and allowed to gel overnight at $37^{\circ} \mathrm{C}$. The resulting gels were then frozen overnight at $-80^{\circ} \mathrm{C}$ and placed on a Labconco lyophilizer for at least 24 hours. After removal from the lyophilizer, the samples were cut horizontally with a scalpel blade to expose the internal structure, mounted on an SEM stub, immediately sputter coated for 30 seconds at $45 \mathrm{mV}$ (Desk II, Denton Vacuum, Moorsetown, NJ), and imaged at $5.0 \mathrm{kV}$ with a Zeiss Supra 35 (Carl Zeiss Microscopy, Thornwood, NY) in the Miami University Center for Applied Microscopy and Imaging. Mercury porosimetry was conducted on $10 \%(\mathrm{w} / \mathrm{v})$ scaffolds prepared as described above. The freeze-dried scaffolds were analyzed by Micromeritics (Norcross, GA) using standard techniques.

\subsection{Cell Viability}

MC3T3-E1 mouse pre-osteoblasts (ATCC, Manassas, VA) at passage number less than 9 were used for cell viability experiments. Cells were grown as a monolayer on tissue-culture treated polystyrene (BD Biosciences, Franklin Lakes, NJ) cultured in a-MEM supplemented with $10 \%$ fetal bovine serum and 1\% penicillin-streptomycin (Life Technologies, Carlsbad $\mathrm{CA}$ ), as recommended by the supplier. Keratin hydrogels were prepared as described above but with cells in culture media used to form the hydrogels. We note that 0:100 KOS:KTN (i.e., KTN) hydrogels were not used in these experiments because KTN does not gel in solution containing salt such as PBS or (in this case) culture media. Gels were formed with a final concentration of $2.5 \times 10^{6}$ cells $/ \mathrm{mL}$ for each available formulation. $300 \mu \mathrm{L}$ of each gel was placed into one well of a 48-well microplate (Fisher Scientific, Hampton, NH). A live cell assay with calcein-AM (Invitrogen, Carlsbad, CA) was then performed either immediately after formation of the materials or at 3,5, or 7 days after initial incubation. We note that after gel formation, no additional media was added onto or into the hydrogels in order to determine viable cells located in the hydrogel. Addition of media led to hydrogel erosion, making it difficult to determine whether viable cells were associated with the hydrogel or were outside of the hydrogel (e.g., on plastic surface). Thus, the hydrogels were still in tact, $15 \%(w / v)$ gels at the time of assay.

For the live cell assay, 3 parts of calcein-AM stock was diluted in 10 parts PBS to give the working solution. The materials and cells were then incubated for 1 hour at $37^{\circ} \mathrm{C}$. After incubation, a portion of the gel $(\sim 50 \mu \mathrm{L})$ was placed into a new well for imaging with a 10X objective on a Zeiss Axiovert microscope. The use of this small amount of gel was necessary 
due to the opacity of the keratin hydrogels. We note that dead staining (e.g., with ethidium bromide homodimer) was conducted, but no signal could be obtained for dead cells even with a positive control (cell death induced by 20 minute incubation with $70 \%$ ethanol in water) except at concentrations of ethidium bromide that were themselves toxic. We attribute this to nonspecific binding between negatively charged keratin and positively charged ethidium bromide preventing specific staining of dead cells. We also note that simple, quantifiable colorimetric assays such as MTS were not suitable for these experiments due to absorption of dyes as well as interference in absorbance readings by the keratin proteins eroding out of the gels (see Section 2.6) that have overlap in the absorbance spectra of the MTS.

\subsection{Keratin Hydrogel Erosion and Thiol Content Assays}

Keratin hydrogel formulations (Table 1) were formed as described above with deionized water used to form the various KOS:KTN gels. $100 \mu \mathrm{L}$ of gel was added from a syringe to $1.5 \mathrm{~mL}$ test tubes and allowed to gel overnight at $37^{\circ} \mathrm{C} .150 \mu \mathrm{L}$ of sterile PBS was then added to each test tube on top of the keratin gels. The PBS was then removed and replaced with fresh PBS at pre-assigned time points ( $\sim 1.5$ hours, 3 hours, 6 hours, 12 hours, 24 hours, then daily for one week). Samples were frozen at $-80^{\circ} \mathrm{C}$ until time of analysis. Protein concentration (indicating eroded keratin) from the hydrogels was measured by using a Lowry protein assay (DC Protein Assay, Bio-Rad, Hercules, CA). The mass percent eroded data were then calculated based on the known initial mass of the gel (15 mg of keratin in 100 $\mu \mathrm{L}$ of a $15 \mathrm{w} / \mathrm{v} \%$ gel).

The thiol content of the starting materials and the proteins eluted from the hydrogels used for erosion data (previous paragraph) were determined by Ellman's assay. ${ }^{39}$ For starting materials (keratose or kerateine), the proteins were dissolved at $2 \mathrm{mg} / \mathrm{mL}$ in water. One hundred microliters of these starting materials or the eluted proteins (protein concentration determined as described above) from the erosion assay above were placed in $300 \mu \mathrm{L}$ phosphate buffer ( $\mathrm{pH}=7.6$; final concentration $8.0 \mathrm{mM}$ of sodium phosphate monohydrate). $1 \mu \mathrm{L}$ of $100 \mathrm{mM}$ Ellman's reagent (Sigma, St. Louis, MO) was added and allowed to react for 10 minutes. Two-hundred $\mu \mathrm{L}$ of this mixture was then placed in the well of a 96-well plate and thiol content was determined by an absorbance reading at $412 \mathrm{~nm}$ with comparison to a cysteine standard curve.

\subsection{Release of rhIGF-1 from keratin hydrogels}

Recombinant human insulin-like growth factor 1 (rhIGF-1) was dissolved in water at 100 $\mu \mathrm{g} / \mathrm{mL}$ and this solution was then used to form keratin hydrogels as described in Section 2.1 (see also Table 1). $100 \mu \mathrm{L}$ of the resulting material was placed in a $1.5 \mathrm{~mL}$ tube and allowed to gel overnight at $37^{\circ} \mathrm{C} .150 \mu \mathrm{L}$ of PBS was then layered on top of the hydrogels as described in the protein assay above (section 2.6). The PBS was then removed and replaced with fresh PBS at pre-determined time points ( 1.5 hours, 3 hours, 6 hours, 12 hours, 24 hours, then daily for one week). Samples were frozen at $-80^{\circ} \mathrm{C}$ until time of analysis. The amount or rhIGF-1 release from the gels was determined an enzyme-linked immunosorbant assay (ELISA) selective for IGF-1 (R\&D Systems, Minneapolis, MN) using the manufacturer's instructions with comparison to a standard curve of known amount of 
rhIGF-1. Absorbance readings were taken on a Bio-Tek Synergy HT Platereader (Winooski, VT) in 96-well plates.

\subsection{Statistical Analysis}

Statistical analyses were performed with MiniTab. One-way ANOVA followed by Tukey's post-hoc test was used to assess differences between the different keratin hydrogel groups where appropriate. $\mathrm{P}<0.05$ was taken to be statistically significant.

\section{Results}

\subsection{Rheology}

Rheological characterization was used to identify changes in the viscoelastic properties of the keratin hydrogels formed by KOS, KTN, or mixtures of the two. These studies were important toward assessing the role that physical compared to covalent crosslinking would play if indeed disulfide crosslinks are present in these materials.

We performed a frequency sweep from 0.01 to $10 \mathrm{~Hz}$ and results are shown in Figure 2 for G' (elastic or stored modulus, Figure 2A) and G" (viscous modulus, Figure 2B). Based on the chemistry of KOS and KTN, it was expected that formulations with higher levels of KOS would have lower levels of covalent disulfide crosslinks due to the presence of sulfonic acid groups whereas formulations with higher levels of KTN would have high levels of disulfide crosslinks. The results shown in Figure 2A for the rheological elastic moduli of the various KOS:KTN formulations as consistent with this expectation. KTN had the highest elastic modulus while KOS had the lowest elastic modulus, as expected. Similarly, the KOS:KTN ratios followed the expected trend of increasing elastic modulus with increasing levels of KTN, likely due to increased elasticity as a result of increasing levels of disulfide crosslinks as KTN content increases.

Both the elastic modulus (G'; Figure 2A) and viscous modulus (G'; Figure 2B) had some frequency dependence. However, the frequency dependence was clearly less in the formulations containing increasing levels of kerateine (decreasing levels of keratose). This behavior is consistent with increasing levels of covalent crosslinking in formulations containing more kerateine and this, in turn, may be attributed to the increasing levels of free thiol and resulting disulfide bonds in kerateine formulations. Likewise, the greater frequency dependence in keratose is consistent with greater chain mobility associated with physically, but not covalently, crosslinked hydrogels. ${ }^{40,41}$ G' is also greater than G" in each formulation, which is consistent with these types of viscoelastic hydrogels. ${ }^{42}$

Statistical analysis comparing the various formulations (one-way ANOVA followed by Tukey's post-hoc test) was conducted at 0.1 and $1 \mathrm{~Hz}$ and the results are indicated in Figure 2. There is a clear trend of increasing modulus with increasing disulfide crosslinking, and in general, the differences are statistically significant between groups except their nearest formulation. Thus, these data support the assertion that by mixing different amounts of KOS and KTN it is possible to control the level of disulfide crosslinking. 


\subsection{Compressive Mechanical Properties of Keratin Hydrogels and Scaffolds}

We further assessed the mechanical properties of the keratin mixture formulations by determining the compressive moduli for both hydrogels and scaffolds. In part, the rationale for assessing both physical forms is that both hydrogels ${ }^{43}$ and scaffolds ${ }^{44}$ have been previously reported for TERM applications in the literature. Figure $3 \mathrm{~A}$ shows the compressive modulus for freeze-dried scaffolds and Figure 3B shows the compressive modulus for the hydrogels. As would be expected, the freeze-dried formulations (solid form) had 10 to 100-fold higher moduli than the hydrogels due to the presence of water and subsequent chain mobility in the hydrogels as noted in the rheological characterization above. For the scaffold forms (Figure 3A), the compressive modulus for each of the KOS:KTN mixtures (70:30, 50:50, and 30:70) was significantly less than KTN, but was not statistically different from KOS or the other mixture formulations. Similarly, for the hydrogel forms of the materials, all formulations were significantly different than KTN, but none of the remaining formulations were significantly different from the others. The results of KTN have greater mechanical strength than KOS is consistent with previous reports and is not unexpected. We suspect that the higher modulus (or much higher in the case of the hydrogels) for the KTN formulations is related to the ability of the KTN chains to interact with each other through interactions other than disulfide crosslinks. In turn, the lower compressive moduli for the KOS:KTN mixtures may be related to interactions between KOS and KTN being weaker than homogenous KTN gels related to the presence of higher order structures of KTN typically found in these extracts. ${ }^{37}$ Other explanations could include a decrease in hydrophobic interactions with the incorporation of the more hydrophilic sulfonic acid groups of keratose (see Discussion).

\subsection{SEM Imagings}

While the rheological properties varied as a function of disulfide crosslinking, we used SEM to qualitatively determine whether this crosslinking had an effect on three-dimensional macro-porous architecture. As shown in Figure 4, the various formulations had similar pore diameters of approximately $20 \mu \mathrm{m}$ (though some contraction during lyophilization is likely). Some differences can be seen in the architecture, but the images are all consistent with a porous network consistent with hydrogels that have been lyophilized for SEM imaging. Thus, although at the molecular level the presence of the disulfide crosslinks had dynamic mechanical effects (Figures 2 and 3), these effects did not lead to observable differences at the macroporous level indicated by the pore diameters on SEM.

Mercury porosimetry was used to provide quantitative analysis of the porosity observed qualitatively in the SEM images for the five hydrogel formulations. As expected, given that the gels subjected to porosimetry were 10\% w/v (90\% water), all gels were between 76-89\% porous (Supplemental Figure 1). The small but statistically significant differences between the formulations may be due to drying variability inherent in laboratory lyophilizers. Taken together, the SEM and mercury porosimetry data indicate that the hydrogel matrix is stable in a fashion independent of the amount of disulfide crosslinking. 


\subsection{Cell Viability}

These hydrogel materials may be of interest as a cell delivery system, ${ }^{24}$ and the viability of cells during gelation as well as after implantation is important. We assessed whether the keratin mixture formulations could support cell viability by using a live cell assay with calcein-AM on cells suspended in the hydrogels. In these experiments, MC3T3-E1 cells were loaded into keratin gels during the hydration process at pre-defined concentrations of $2.5 \times 10^{6}$ cells $/ \mathrm{mL}$. As can be seen in Figure 5, we were unable to form 100\% KTN (0:100) hydrogels with encapsulated cells due to the presence of salts in the culture media. However, by incorporating the cell suspension in to the KOS portion and mixing with KTN (in water), we were able to successfully incorporate MC3T3-E1 cells into the 4 other keratin formulations tested. Viable cells were observed both initially after fabricating the materials (Day 0) as well as over the course of one week in culture. Because no culture media was overlaid on top of the gels, the materials remained in tact (no erosion) over the course of the 7 day incubation. The pore structure (see Figure 4) of these materials and the lack of additional culture media may have prevented proliferation or migration of cells within the materials over the course of the 7 days. The images are representative of the amount and distribution of cells after an incubation period of one week. We have previously measured the viability of cells cultured on 2D 100\% KTN gels and observed no loss in viability, ${ }^{33}$ but we note that we were unable to detect dead cells in these 3D hydrogels even on positive controls for cell death (70\% ethanol incubation for 20 minutes), presumably because the positively charged ethidium bromide interacts with the negatively charged keratin surface, preventing cellular uptake.

\subsection{Gel Erosion and Thiol Content}

Given previous observations showing relatively rapid erosion of $\operatorname{KOS}^{14}$ and relatively slow erosion of KTN, ${ }^{24,} 36$ in conjunction with our observations on the effects of KOS:KTN mixtures on disulfide crosslinking as determined by rheology (Figure 2), we tested the erosion rates of the five keratin hydrogel formulations. As shown in Figure 6A, increasing amounts of KOS led to a clear increase in erosion rate. That is, decreasing levels of disulfide crosslinking were inversely proportional to the rate of erosion. Figure $6 \mathrm{~A}$ is presented as percent erosion, and this indicates the amount of soluble protein released into PBS and detectable by the Lowry assay, with $100 \%$ erosion indicating complete solubility of the gels. This result goes one step further than previous studies with KOS or KTN alone by showing that the rate of erosion can be "fine-tuned" by mixing KOS and KTN and taking advantage of the unique properties afforded keratin through its cysteine residues. The difference in erosion rate between pure KOS and KTN is evident, with $~ 70 \%$ of the KOS gel having eroded after one week, compared to $\sim 7 \%$ of the KTN gel. The various ratios of KOS:KTN erode at rates that correspond to the amount of KOS in the gel, with $\sim 50 \%, \sim 33 \%$, and $\sim 22 \%$ erosion for 70:30, 50:50, and 30:70 gels, respectively, by one week. The erosion profiles of KOS are similar to those previously reported by our group in vitro. ${ }^{45}$ This result indicates that mixing KOS and KTN still leads to hydrogel formation, but with tunable rates of erosion depending on the relative amount of each component.

We also assessed the thiol content of the staring materials (keratose or kerateine) and the eroded materials from the hydrogels. We reasoned that the thiol content of the starting 
materials would provide indication of the potential to form disulfide crosslinks while the thiol content of the eroded material would help to describe which protein (keratose or kerateine was eroding). The thiol content of kerateine was found to be $139 \pm 14.1 \mathrm{nmol}$ thiol $/ \mathrm{mg}$ protein while the thiol content of keratose was found to be $12.7 \pm 1.5 \mathrm{nmol}$ thiol/mg protein. This is consistent with the expected result that kerateine has much greater thiol content than keratose due to sulfonic acid residues on cysteine residues of keratose. Based on these thiol contents, we were able to determine the starting amount of thiol in each keratin hydrogel formulation, and these values are shown in Table 1.

Figure 6B shows the cumulative thiol release for each formulation where the percentage is based on the amount of thiol in the starting formulation (see Table 1). While the thiol content of the starting materials (and presumably the resultant hydrogels) increases with increasing amounts of kerateine (see Table 1), the protein release decreases. Conversely, despite decreasing amount of thiol in the starting materials, the cumulative thiol release (Figure 6B) becomes increasingly higher with increasing amounts of keratose in the formulation. The fact that the percent thiol release is less than the percent protein release (compare Figure 6A and 6B) indicates that higher thiol content proteins are remaining associated with the hydrogel while lower thiol content proteins are being released. Our interpretation of this result is that keratose is eroding more rapidly from the mixture formulations than the kerateine.

\section{6 rhIGF-1 Release}

In this study, we elected to investigate rhIGF-1 release because this growth factor has been used in several TERM applications $46,47,48,49,50,51$. We note that we have previously found that the affinity of rhIGF-1 is higher for kerateine than keratose, but that the relative affinity of rhIGF-1 is orders of magnitude lower than other growth factors such as recombinant human bone morphogenetic protein 2 (rhBMP-2) ${ }^{33}$. This relatively low interaction allowed us to investigate the ability to tune its release in a manner less dependent on molecular interactions between rhIGF-1 and keratin as compared to interactions between keratin and other growth factors. As shown in Figure 7, the release of rhIGF-1 could be tuned by the keratin formulation. By the $\sim 12$ hour time point (and at all subsequent time points) each formulation was different than the other, with the exception that the 30:70 and 50:50 KOS:KTN formulations did not achieve statistical difference until the sixth day of the study. We do note that for two other compounds (rhBMP-2 and ciprofloxacin antibiotic) that have been found to have molecular interactions with keratin, we did not observe as predictable of release profiles (data not shown), indicating that the agent being released also play a key role when attempting to tune the rate of release.

\section{Discussion}

The use of TERM approaches to promote healing of large injuries that cannot be repaired naturally or with existing surgical techniques (e.g., as a result of trauma) has led to the investigation of new biodegradable materials that can act as a conductive matrix for cells while providing cues (e.g., from the release of exogenous growth factors) to promote healing. In a broad sense, two basic types of polymeric materials are being investigated to 
aid in TERM- mediated healing processes: (1) synthetic and (2) natural polymers. In this report, we have described a simple approach to use the inherent properties of natural keratin proteins to fabricate hydrogel materials that can be tuned in a fashion reminiscent of synthetic polymers for control over rate of erosion and delivery of a therapeutic agent (rhIGF-1). This approach does not require addition of external crosslinkers such as light, enzymes, or chemicals. Rather, it relies simply on the inherent properties of keratin proteins following either oxidative (KOS) or reductive (KTN) extraction and the resulting state of the cysteine residues (uncrosslinked or disulfide crosslinked for KOS and KTN, respectively).

We initially characterized these KOS and KTN hydrogel mixture formulations in terms of their rheological properties, mechanical properties, and pore structure/porosity. The rheological properties indicate the formation of a stable hydrogel network. As increasing amounts of KTN (decreasing amounts of KOS) are present in the hydrogels, G' (elastic modulus) increases. This is consistent with increasing levels of covalent (rather than just physical) crosslinking, which others have reported for natural polymers, ${ }^{52}$ synthetic polymers, ${ }^{53}$ and natural-synthetic hybrid materials. ${ }^{54}$ In particular, increasing levels of thiol crosslinking in a synthetic polymer have previously shown decreasing frequency dependence with increasing levels of crosslinking. ${ }^{55}$ As such, we interpret the results of our studies to be consistent with the concept of increasing levels of disulfide crosslinking (via cysteine residues) in hydrogels containing more kerateine. We also note that these keratin materials have rheological characteristics (elastic and viscous moduli) consistent with those materials noted above used for drug delivery and tissue engineering.

These differences at the molecular level (chemical state of the cysteine residues and levels of disulfide crosslinking) did not lead to observable differences in the pore diameters or porosity as determined by SEM and mercury porosimetry, respectively, though some differences in pore structure could be observed. However, like the rheological data, the differences at the molecular level did appear to affect the mechanical properties of these materials. First, the materials were very dependent on the physical state of the materials (freeze-dried scaffold vs. hydrogel). The moduli were much lower for the hydrogels due to the increased mobility of the hydrated matrix present in the hydrogel form of the materials. As expected, KTN had the greatest mechanical strength, but it was interesting to note that there were no significant differences in the moduli for either scaffolds or hydrogels of the mixture formulations (70:30, 50:50, or 30:70 KOS:KTN), though the moduli of the mixtures were significantly less than KOS (0:100 KOS:KTN) for the hydrogels. One possible explanation for this is that the mechanical properties of the formulations are highly dependent on the interaction of individual keratin molecules at the microscopic level. It is known that keratins spontaneously self-assemble in the formation of hierarchical structures of biological structures such as hair and wool ${ }^{56}$ with hydrophobic and other intermolecular interactions playing a role in this behavior. ${ }^{57,58}$ However, it is also known that $\mathrm{KOS}^{14}$ and $\mathrm{KTN}^{37}$ extracts are present as higher order structures. These self-assembled dimeric (tetrameric, etc.) structures may lead to increased strength at the molecular level in a manner similar to the hierarchical biological structures such as hair. Thus, the mixing of keratose and kerateine, while not having large effects at the macroporous level (see SEM images and porosity data shown Figure 4), could affect molecular interactions and thus the mechanical properties. This behavior could allow more chain mobility, leading to the lower modulus 
values observed for the keratin hydrogel mixtures. It is also possible that other molecular interactions are causing this effect. For example, it is known that kerateine is more hydrophobic than keratose, likely due in part to the relatively hydrophilic sulfonic acid groups. Thus, the presence of keratose in combination with kerateine could decrease hydrophobic or other inter/intramolecular interactions.

The basis of the hypothesis guiding this work was that differences in disulfide crosslinking capabilities of KOS and KTN extracts could be exploited to modulate rates of hydrogel erosion. The results of the erosion experiment (Figure 6) clearly demonstrate this behavior. In TERM applications it may be considered ideal to have a tunable matrix material to provide optimal in vivo tissue healing (or regeneration) such that the material degrades as new tissue forms. This could also be advantageous for three-dimensional in vitro cell culture approaches to tissue formation. ${ }^{59}$ This simple approach to achieve keratin-based materials with tunable erosion allows such an approach with a natural polymer system. Given that the pore structures and porosities of each of the gels were similar, the difference in gel erosion should not be due differences in the mechanism of erosion such as bulk erosion occurring in one formulation and surface erosion in another ${ }^{60}$ Although KTN is generally more hydrophobic than KOS, the similar pore sizes and porosities of the KTN, KOS, and mixtures suggest that the differences in erosion are directly related to the levels of disulfide crosslinking and elution of the proteins out of the hydrogels based on the ratios of KOS and KTN. This idea is supported by the thiol release experiment (Figure 6B). It is clear that the released thiol percentage (based on the thiol content of the starting materials; Figure 6B and Table 1) is lower than the released protein percentage (Figure 6A) for each formulation. Our interpretation is that this is because higher thiol content proteins remain associated with the gels as disulfide crosslinks while less crosslinked materials erode more quickly. We have been unsuccessful in determining the thiol crosslinking of the actual hydrogels directly, though the rheological data supports this idea. Although we only tested five formulations in the range of $100 \% \mathrm{KOS}(0 \% \mathrm{KTN})$ to $0 \% \mathrm{KOS}(100 \% \mathrm{KTN})$, we do not have reason to believe that there would be any challenges associated with "fine tuning" the formulations for even greater control over the rate of erosion.

These findings have several implications. First, keratins, both KOS and KTN, have been investigated as a biomaterial for applications including nerve regeneration, ${ }^{61,62}$ skin wound healing, ${ }^{25,} 63$ hemostasis, ${ }^{64,} 65$ cardiac repair, ${ }^{66}$ and bone regeneration. ${ }^{28,}, 30$ These previous studies have relied on a single form of extracted keratin (KOS or KTN), limiting the rates of erosion to those inherent for each method of extraction (KOS or KTN). Our study demonstrates the ability to readily tune this material to specific erosion properties meaning that the material can be tuned to the biomedical need rather than vice versa. In addition, although not studied here, there are additional components of the keratin system that can be modified to further tune material properties such as the weight percent of the gels or the relative ratio of alpha and gamma fractions of keratin proteins. ${ }^{37}$ For consistency and to avoid a larger number of experimental parameters, all experiments in this study were conducted with keratin materials containing only alpha proteins (higher molecular weight proteins); no gamma keratins (lower molecular weight keratin proteins) were used. It is important to note that the source material and methods of extraction yield a heterogenous mix of proteins that include keratins and also keratin-associated proteins. Previous reports 
using these extraction techniques indicate that essentially the same proteins make up both keratose and kerateine (which include keratins 31, 33a, 33b, 34, 81, 83, 85, and 86 as well as keratin-associated proteins) and that both degradation products and higher order structures are found in these extracts 14,37 .

It should also be noted that although the rheological properties indicate crosslinked networks, these materials are still flowable in nature. This has potential clinical importance as these materials can be injected in a minimally invasive fashion into a defect site. This also provides the ability for clinicians or pre-clinical researchers to easily form these materials into the shape necessary to fit a particular defect. We have recently demonstrated this in a craniofacial model with a well-defined defect size and shape, ${ }^{30}$ but this approach would also be applicable in other types of irregularly-shaped injuries.

The role of cell delivery and recruitment is also of particular interest to those in the TERM field. The results of our study are consistent with others recently published on the architecture of keratin gels or scaffolds (freeze-dried gels), which indicate pores from 10 $100 \mu \mathrm{m}$ in diameter. ${ }^{14,37,45}$ This may be sufficient to allow some cellular infiltration if cells are recruited from tissue surrounding a defect even if the material itself persists. However, as the material erodes and pore sizes increase, cells will likely be better able to infiltrate these materials. ${ }^{67}$ This effect is demonstrated in the live cell assay (Figure 5). Cells did not appear to increase in number, possibly due to restrictions of the pores themselves when the cells were within the materials. The lack of proliferation could be due to lack of additional culture media being added, but the results demonstrate that hydrogel materials can be formed with cells remaining viable within these keratin constructs for up to 7 days. This surprising result suggests that these materials could be used to deliver viable cells in vivo directly from within injectable keratin hydrogels. ${ }^{24}$ Given the flowable nature of these materials within tunable erosion timeframes noted above, this has clear advantages for tissue repair strategies. More in-depth studies on cell viability and function will be required to further assess the suitability of using these materials for cell delivery.

Our group is particularly interested in the ability to tune delivery of therapeutic agents. We elected to assess the release of rhIGF-1 in these studies for several reasons. rhIGF-1 has been investigated for its ability to promote regeneration in several models including those for musculoskeletal, ${ }^{46,47,48}$ cardiovascular, ${ }^{49,}{ }^{50}$ and neural ${ }^{51}$ applications. We also recently found that rhIGF-1 has minimal interactions with keratin proteins, though interactions are greater for KTN than for KOS. ${ }^{33}$ This relatively low interaction allowed us to study the effects of only erosion on this molecule with minimal concern for other effects (e.g., molecular interactions) that might affect release. With recent efforts to better mimic processes of development, increasing numbers of exogenously delivered bioactive molecules will be used in tissue engineering constructs. Although regulatory issues associated with growth factors remain a key challenge to implementation, the ability to achieve temporal control over delivery of these agents is a key technical challenge that is critical to the behavior of cells or tissue upon which these molecules act. The ability to tune such delivery within the context of a natural proteinaceous polymeric material without requirements for external crosslinkers is rare, but would provide a new avenue to study effects of delivery profiles on regenerative processes. Importantly, the release of rhIGF-1 from these KOS-KTN 
formulations was correlated with the rate of keratin erosion. It is noteworthy, however, that the release of rhIGF-1 was slowed with increasing amounts of kerateine. We attribute this to the fact that rhIGF-1 has a greater binding affinity for kerateine than keratose ${ }^{33}$.

We do note that two other molecules (ciprofloxacin antibiotic and rhBMP-2) that were previously found to have some molecular interactions ${ }^{33,45}$ with keratin had less predictable and tunable profiles than rhIGF-1 (data not shown). Because the physiochemical characteristics of both the keratin carrier and the therapeutic agent appear to play a role, further studies would be required to better predict release. Nonetheless, given that different bioactive molecules require different timetables and therapeutic doses, being able to tailor the rate of delivery in a manner related to hydrogel erosion is a potential advantage of this keratin system in TERM strategies.

\section{Conclusions}

The data presented here demonstrates, for the first time, the ability to achieve tunable erosion of keratin hydrogels through the use of mixtures of keratose and kerateine. Our rheological and thiol content data suggest that this tunability is related to the chemical nature of the cysteine residues in keratin and the chemical differences in these residues resulting from the extraction conditions. The formulation of these hydrogels is simple and straightforward and provides a potential tool to investigate effects of controlled erosion, therapeutic agent delivery, and cell delivery within the context of a tunable natural, rather than synthetic, material. These studies have implications for tissue engineering and regenerative medicine approaches where control over drug and cell delivery must be tightly regulated.

\section{Supplementary Material}

Refer to Web version on PubMed Central for supplementary material.

\section{Acknowledgments}

The authors acknowledge the Center for Applied Microscopy and Imaging (Dr. Richard Edelmann and Matthew Duley) for assistance and resources for SEM imaging. The authors also thank Ms. Judy Bohnert for sample preparation and mechanical testing.

\section{Funding Sources}

This work was partially supported by the National Institutes of Health (JMS; R01AR061391) and the content is solely the responsibility of the authors and does not necessarily represent the official views of the National Institutes of Health. This work was also partially supported by the US Army Medical Research and Materiel Command under Contract No. W81XWH-11-C-0060 (ST; Spatiotemporally Controlled Keratin Biomaterial Delivery System for Functional Tissue Regeneration Phase II). The views, opinions and/or findings contained in this report are those of the author(s) and should not be construed as an official Department of the Army position, policy or decision unless so designated by other documentation.

\section{ABBREVIATIONS}
$\beta M E$
beta mercaptoethanol
ELISA
enzyme-linked immunosorbant assay 


$\begin{array}{ll}\text { G' } & \text { elastic modulus } \\ \text { G” } & \text { viscous modulus } \\ \mathbf{H}_{2} \mathbf{O}_{2} & \text { hydrogen peroxide } \\ \text { KOS } & \text { keratose } \\ \text { KTN } & \text { kerateine } \\ \text { PAA } & \text { peracetic acid } \\ \text { rhBMP-2 } & \text { recombinant human bone morphogenetic protein 2 } \\ \text { rhIGF-1 } & \text { recombinant human insulin-like growth factor 1 } \\ \text { SEM } & \text { scanning electron microscopy } \\ \text { TERM } & \text { tissue engineering and regenerative medicine } \\ \text { TGA } & \text { thioglycolic acid }\end{array}$

\section{References}

1. Chen RR, Mooney DJ. Polymeric growth factor delivery strategies for tissue engineering. Pharm. Res. 2003; 20(8):1103-12. [PubMed: 12948005]

2. Perez RA, Won JE, Knowles JC, Kim HW. Naturally and synthetic smart composite biomaterials for tissue regeneration. Adv. Drug Del. Rev. 2013; 65(4):471-96.

3. Kricheldorf HR, Berl M, Scharnagl N. Poly(Lactones) .9. Polymerization Mechanism of Metal Alkoxide Initiated Polymerizations of Lactide and Various Lactones. Macromolecules. 1988; 21(2): 286-293.

4. Mariner PD, Wudel JM, Miller DE, Genova EE, Streubel SO, Anseth KS. Synthetic hydrogel scaffold is an effective vehicle for delivery of INFUSE (rhBMP2) to critical-sized calvaria bone defects in rats. J. of Orthop. Res. 2013; 31(3):401-6. [PubMed: 23070779]

5. Azagarsamy MA, Alge DL, Radhakrishnan SJ, Tibbitt MW, Anseth KS. Photocontrolled nanoparticles for on-demand release of proteins. Biomacromolecules. 2012; 13(8):2219-24. [PubMed: 22746981]

6. Fabiilli ML, Wilson CG, Padilla F, Martin-Saavedra FM, Fowlkes JB, Franceschi RT. Acoustic droplet-hydrogel composites for spatial and temporal control of growth factor delivery and scaffold stiffness. Acta Biomater. 2013; 9(7):7399-409. [PubMed: 23535233]

7. Bessa PC, Machado R, Nurnberger S, Dopler D, Banerjee A, Cunha AM, Rodriguez-Cabello JC, Redl H, van Griensven M, Reis RL, Casal M. Thermoresponsive self-assembled elastin-based nanoparticles for delivery of BMPs. J. Controlled Release. 2010; 142(3):312-8.

8. Zhang J, Neoh KG, Hu X, Kang ET, Wang W. Combined effects of direct current stimulation and immobilized BMP-2 for enhancement of osteogenesis. Biotechnol. Bioeng. 2013; 110(5):1466-75. [PubMed: 23192383]

9. Bi X, Amie Luckanagul J, Allen A, Ramaboli M, Campbell E, West D, Maturavongsadit P, Brummett K, Wang Q. Synthesis of PAMAM dendrimer-based fast cross-linking hydrogel for biofabrication. J. Biomater. Sci., Polym. Ed. 2015; 26(11):669-82. [PubMed: 26023858]

10. Jones DR, Marchant RE, von Recum H, Sen Gupta A, Kottke-Marchant K. Photoinitiator-free synthesis of endothelial cell-adhesive and enzymatically degradable hydrogels. Acta Biomater. 2015; 13:52-60. [PubMed: 25462848]

11. de Luca AC, Faroni A, Downes S, Terenghi G. Differentiated adipose-derived stem cells act synergistically with RGD-modified surfaces to improve neurite outgrowth in a co-culture model. J. Tissue. Eng. Regen. Med. 2013 
12. Rosellini E, Cristallini C, Guerra GD, Barbani N. Surface chemical immobilization of bioactive peptides on synthetic polymers for cardiac tissue engineering. J. Biomater. Sci., Polym. Ed. 2015; 26(9):515-33. [PubMed: 25787756]

13. Callahan LA, Xie S, Barker IA, Zheng J, Reneker DH, Dove AP, Becker ML. Directed differentiation and neurite extension of mouse embryonic stem cell on aligned poly(lactide) nanofibers functionalized with YIGSR peptide. Biomaterials. 2013; 34(36):9089-95. [PubMed: 24008044]

14. de Guzman RC, Merrill MR, Richter JR, Hamzi RI, Greengauz-Roberts OK, Van Dyke ME. Mechanical and biological properties of keratose biomaterials. Biomaterials. 2011; 32(32):820517. [PubMed: 21835462]

15. Sierpinski P, Garrett J, Ma J, Apel P, Klorig D, Smith T, Koman LA, Atala A, Van Dyke M. The use of keratin biomaterials derived from human hair for the promotion of rapid regeneration of peripheral nerves. Biomaterials. 2008; 29(1):118-28. [PubMed: 17919720]

16. Giannoudis PV, Einhorn TA, Marsh D. Fracture healing: the diamond concept. Injury. 2007; 38(Suppl 4):S3-6.

17. Haidar ZS, Hamdy RC, Tabrizian M. Delivery of recombinant bone morphogenetic proteins for bone regeneration and repair. Part A: Current challenges in BMP delivery. Biotechnol. Lett. 2009; 31(12):1817-24. [PubMed: 19690804]

18. Atala A, Bauer SB, Soker S, Yoo JJ, Retik AB. Tissue-engineered autologous bladders for patients needing cystoplasty. Lancet. 2006; 367(9518):1241-6. [PubMed: 16631879]

19. Macchiarini P, Jungebluth P, Go T, Asnaghi MA, Rees LE, Cogan TA, Dodson A, Martorell J, Bellini S, Parnigotto PP, Dickinson SC, Hollander AP, Mantero S, Conconi MT, Birchall MA. Clinical transplantation of a tissue-engineered airway. Lancet. 2008; 372(9655):2023-30. [PubMed: 19022496]

20. Gonfiotti A, Jaus MO, Barale D, Baiguera S, Comin C, Lavorini F, Fontana G, Sibila O, Rombola G, Jungebluth P, Macchiarini P. The first tissue-engineered airway transplantation: 5-year followup results. Lancet. 2014; 383(9913):238-44. [PubMed: 24161821]

21. Pace LA, Plate JF, Mannava S, Barnwell JC, Koman LA, Li Z, Smith TL, Van Dyke M. A human hair keratin hydrogel scaffold enhances median nerve regeneration in nonhuman primates: an electrophysiological and histological study. Tissue Eng., Part A. 2014; 20(3-4):507-17. [PubMed: 24083825]

22. Pace LA, Plate JF, Smith TL, Van Dyke ME. The effect of human hair keratin hydrogel on early cellular response to sciatic nerve injury in a rat model. Biomaterials. 2013; 34(24):5907-14. [PubMed: 23680369]

23. Lin YC, Ramadan M, Van Dyke M, Kokai LE, Philips BJ, Rubin JP, Marra KG. Keratin gel filler for peripheral nerve repair in a rodent sciatic nerve injury model. Plast. Reconstr. Surg. 2012; 129(1):67-78. [PubMed: 22186500]

24. Tombyln S, Kneller EP, Walker SJ, Ellenburg MD, Kowalczewski CJ, Van Dyke M, Burnett L, Saul JM. Keratin hydrogel carrier system for simultaneous delivery of exogenous growth factors and muscle progenitor cells. J. Biomed. Mater. Res., Part B: Appl. Biomat. Published Online May 7, 2015.

25. Poranki D, Whitener W, Howse S, Mesen T, Howse E, Burnell J, Greengauz-Roberts O, Molnar J, Van Dyke M. Evaluation of skin regeneration after burns in vivo and rescue of cells after thermal stress in vitro following treatment with a keratin biomaterial. J. Biomater. Appl. 2013; 29(1):2635. [PubMed: 24272161]

26. Xu S, Sang L, Zhang Y, Wang X, Li X. Biological evaluation of human hair keratin scaffolds for skin wound repair and regeneration. Mater. Sci. Eng., Part C: Mater for Biological Appl. 2013; 33(2):648-55.

27. Poranki DR, Van Dyke ME. The effect of gamma keratose on cell viability in vitro after thermal stress and the regulation of cell death pathway-specific gene expression. Biomaterials. 2014; 35(16):4646-55. [PubMed: 24631248]

28. de Guzman RC, Saul JM, Ellenburg MD, Merrill MR, Coan HB, Smith TL, Van Dyke ME. Bone regeneration with BMP-2 delivered from keratose scaffolds. Biomaterials. 2013; 34(6):1644-56. [PubMed: 23211447] 
29. Dias GJ, Peplow PV, McLaughlin A, Teixeira F, Kelly RJ. Biocompatibility and osseointegration of reconstituted keratin in an ovine model. J Biomed Mater Res, Part A. 2010; 92(2):513-20.

30. Kowalczewski CJ, Tombyln S, Wasnick DC, Hughes MR, Ellenburg MD, Callahan MF, Smith TL, Van Dyke ME, Burnett LR, Saul JM. Reduction of ectopic bone growth in critically-sized rat mandible defects by delivery of rhBMP-2 from kerateine biomaterials. Biomaterials. 2014; 35(10): 3220-8. [PubMed: 24439399]

31. Chen LL, Lobb RR, Cuervo JH, Lin K, Adams SP, Pepinsky RB. Identification of ligand binding sites on integrin alpha4beta1 through chemical cross-linking. Biochemistry. 1998; 37(24):874353. [PubMed: 9628736]

32. Gronthos S, Stewart K, Graves SE, Hay S, Simmons PJ. Integrin expression and function on human osteoblast-like cells. J Bone Miner Res. 1997; 12(8):1189-97. [PubMed: 9258748]

33. Han S, Ham TR, Haque S, Sparks JL, Saul JM. Alkylation of human hair keratin for tunable hydrogel erosion and drug delivery in tissue engineering applications. Acta Biomater. 2015; 23:201-13. [PubMed: 25997587]

34. Wang S, Wang Z, Foo SE, Tan NS, Yuan Y, Lin W, Zhang Z, Ng KW. Culturing fibroblasts in 3D human hair keratin hydrogels. ACS Appl. Mater. Interfaces. 2015; 7(9):5187-98. [PubMed: 25690726]

35. Richter JR, de Guzman RC, Van Dyke ME. Mechanisms of hepatocyte attachment to keratin biomaterials. Biomaterials. 2011; 32(30):7555-61. [PubMed: 21782237]

36. Hill P, Brantley H, Van Dyke M. Some properties of keratin biomaterials: kerateines. Biomaterials. 2010; 31(4):585-93. [PubMed: 19822360]

37. Richter JR, de Guzman RC, Greengauz-Roberts OK, Van Dyke M. Structure-property relationships of meta-kerateine biomaterials derived from human hair. Acta Biomater. 2012; 8(1):274-81. [PubMed: 21911088]

38. Nakata R, Osumi Y, Miyagawa S, Tachibana A, Tanabe T. Preparation of keratin and chemically modified keratin hydrogels and their evaluation as cell substrate with drug releasing ability. $\mathbf{J}$ Biosci. Bioeng. 2015; 120(1):111-6. [PubMed: 25561327]

39. Ellman GL. Tissue sulfhydryl groups. Arch. Biochem. Biophys. 1959; 82(1):70-7. [PubMed: 13650640]

40. Wang QM, Mohan AC, Oyen ML, Zhao XH. Separating viscoelasticity and poroelasticity of gels with different length and time scales. Acta Mech. Sinica-Prc. 2014; 30(1):20-27.

41. Fitzgerald MM, Bootsma K, Berberich JA, Sparks JL. Tunable stress relaxation behavior of an alginate-polyacrylamide hydrogel: comparison with muscle tissue. Biomacromolecules. 2015; 16(5):1497-505. [PubMed: 25812913]

42. Picout DR, Ross-Murphy SB. Rheology of biopolymer solutions and gels. Scientific World J. 2003; 3:105-21.

43. Ozaki Y, Takagi Y, Mori H, Hara M. Porous hydrogel of wool keratin prepared by a novel method: an extraction with guanidine/2-mercaptoethanol solution followed by a dialysis. Mater. Sci. Engin., Part C: Mater Biological Appl. 2014; 42:146-54.

44. Tachibana A, Nishikawa Y, Nishino M, Kaneko S, Tanabe T, Yamauchi K. Modified keratin sponge: binding of bone morphogenetic protein-2 and osteoblast differentiation. J. Biosci. Bioeng. 2006; 102(5):425-9. [PubMed: 17189169]

45. Saul JM, Ellenburg MD, de Guzman RC, Van Dyke M. Keratin hydrogels support the sustained release of bioactive ciprofloxacin. J. Biomed Mater Res., Part A. 2011; 98(4):544-53.

46. Wang L, Cao L, Shansky J, Wang Z, Mooney D, Vandenburgh H. Minimally invasive approach to the repair of injured skeletal muscle with a shape-memory scaffold. Mol. Ther. 2014; 22(8):14419. [PubMed: 24769909]

47. Spiller KL, Liu Y, Holloway JL, Maher SA, Cao Y, Liu W, Zhou G, Lowman AM. A novel method for the direct fabrication of growth factor-loaded microspheres within porous nondegradable hydrogels: controlled release for cartilage tissue engineering. J. Controlled Release. 2012; 157(1): 39-45.

48. Jacquemin V, Furling D, Bigot A, Butler-Browne GS, Mouly V. IGF-1 induces human myotube hypertrophy by increasing cell recruitment. Exp. Cell Res. 2004; 299(1):148-58. [PubMed: 15302582] 
49. Nelson DM, Baraniak PR, Ma Z, Guan J, Mason NS, Wagner WR. Controlled release of IGF-1 and HGF from a biodegradable polyurethane scaffold. Pharmaceutic. Res. 2011; 28(6):1282-93.

50. Karam JP, Muscari C, Sindji L, Bastiat G, Bonafe F, Venier-Julienne MC, Montero-Menei NC. Pharmacologically active microcarriers associated with thermosensitive hydrogel as a growth factor releasing biomimetic 3D scaffold for cardiac tissue-engineering. J Controlled Release. 2014; 192:82-94.

51. Apel PJ, Ma J, Callahan M, Northam CN, Alton TB, Sonntag WE, Li Z. Effect of locally delivered IGF-1 on nerve regeneration during aging: an experimental study in rats. Muscle Nerve. 2010; 41(3):335-41. [PubMed: 19802878]

52. Rammensee S, Huemmerich D, Hermanson KD, Scheibel T, Bausch AR. Rheological characterization of hydrogels formed by recombinantly produced spider silk. Appl. Phys., Part A: Mater. 2006; 82(2):261-264.

53. Zustiak SP, Leach JB. Hydrolytically degradable poly(ethylene glycol) hydrogel scaffolds with tunable degradation and mechanical properties. Biomacromolecules. 2010; 11(5):1348-57. [PubMed: 20355705]

54. Kang EY, Moon HJ, Joo MK, Jeong B. Thermogelling chitosan-g-(PAF-PEG) aqueous solution as an injectable scaffold. Biomacromolecules. 2012; 13(6):1750-7. [PubMed: 22607186]

55. Chiou BS, English RJ, Khan SA. Rheology and photo-cross-linking of thiol-ene polymers. Macromolecules. 1996; 29(16):5368-5374.

56. Lee H, Noh K, Lee SC, Kwon IK, Han DW, Lee IS, Hwang YS. Human Hair Keratin and Its-Based Biomaterials for Biomedical Applications. Tissue Eng. Regen. Med. 2014; 11(4):255-265.

57. Hatzfeld M, Burba M. Function of type I and type II keratin head domains: their role in dimer, tetramer and filament formation. J. Cell. Sci. 1994; 107(Pt 7):1959-72. [PubMed: 7527050]

58. Bernot KM, Lee CH, Coulombe PA. A small surface hydrophobic stripe in the coiled-coil domain of type I keratins mediates tetramer stability. J. Cell Biol. 2005; 168(6):965-74. [PubMed: 15767464]

59. Mieszawska AJ, Kaplan DL. Smart biomaterials - regulating cell behavior through signaling molecules. BMC Biol. 2010; 8:59. [PubMed: 20529238]

60. von Burkersroda F, Schedl L, Gopferich A. Why degradable polymers undergo surface erosion or bulk erosion. Biomaterials. 2002; 23(21):4221-31. [PubMed: 12194525]

61. Pace LA, Plate JF, Mannava S, Barnwell JC, Koman LA, Li Z, Smith TL, Van Dyke M. A human hair keratin hydrogel scaffold enhances median nerve regeneration in nonhuman primates: an electrophysiological and histological study. Tissue. Eng., Part A. 2014; 20(3-4):507-17. [PubMed: 24083825]

62. Hill PS, Apel PJ, Barnwell J, Smith T, Koman LA, Atala A, Van Dyke M. Repair of peripheral nerve defects in rabbits using keratin hydrogel scaffolds. Tissue Eng., Part A. 2011; 17(11-12): 1499-505. [PubMed: 21275820]

63. Thilagar S, Jothi NA, Omar AR, Kamaruddin MY, Ganabadi S. Effect of keratin-gelatin and bFGFgelatin composite film as a sandwich layer for full-thickness skin mesh graft in experimental dogs. J. Biomed. Mater. Res., Part B: Appl Biomater. 2009; 88(1):12-6. [PubMed: 18161832]

64. Burnett LR, Richter JG, Rahmany MB, Soler R, Steen JA, Orlando G, Abouswareb T, Van Dyke ME. Novel keratin (KeraStat) and polyurethane (Nanosan(R)-Sorb) biomaterials are hemostatic in a porcine lethal extremity hemorrhage model. J. Biomater Appl. 2014; 28(6):869-79. [PubMed: 23594681]

65. Rahmany MB, Hantgan RR, Van Dyke M. A mechanistic investigation of the effect of keratinbased hemostatic agents on coagulation. Biomaterials. 2013; 34(10):2492-500. [PubMed: 23332318]

66. Shen D, Wang X, Zhang L, Zhao X, Li J, Cheng K, Zhang J. The amelioration of cardiac dysfunction after myocardial infarction by the injection of keratin biomaterials derived from human hair. Biomaterials. 2011; 32(35):9290-9. [PubMed: 21885119]

67. Nicodemus GD, Bryant SJ. Cell encapsulation in biodegradable hydrogels for tissue engineering applications. Tissue. Eng., Part B: Rev. 2008; 14(2):149-65. [PubMed: 18498217] 


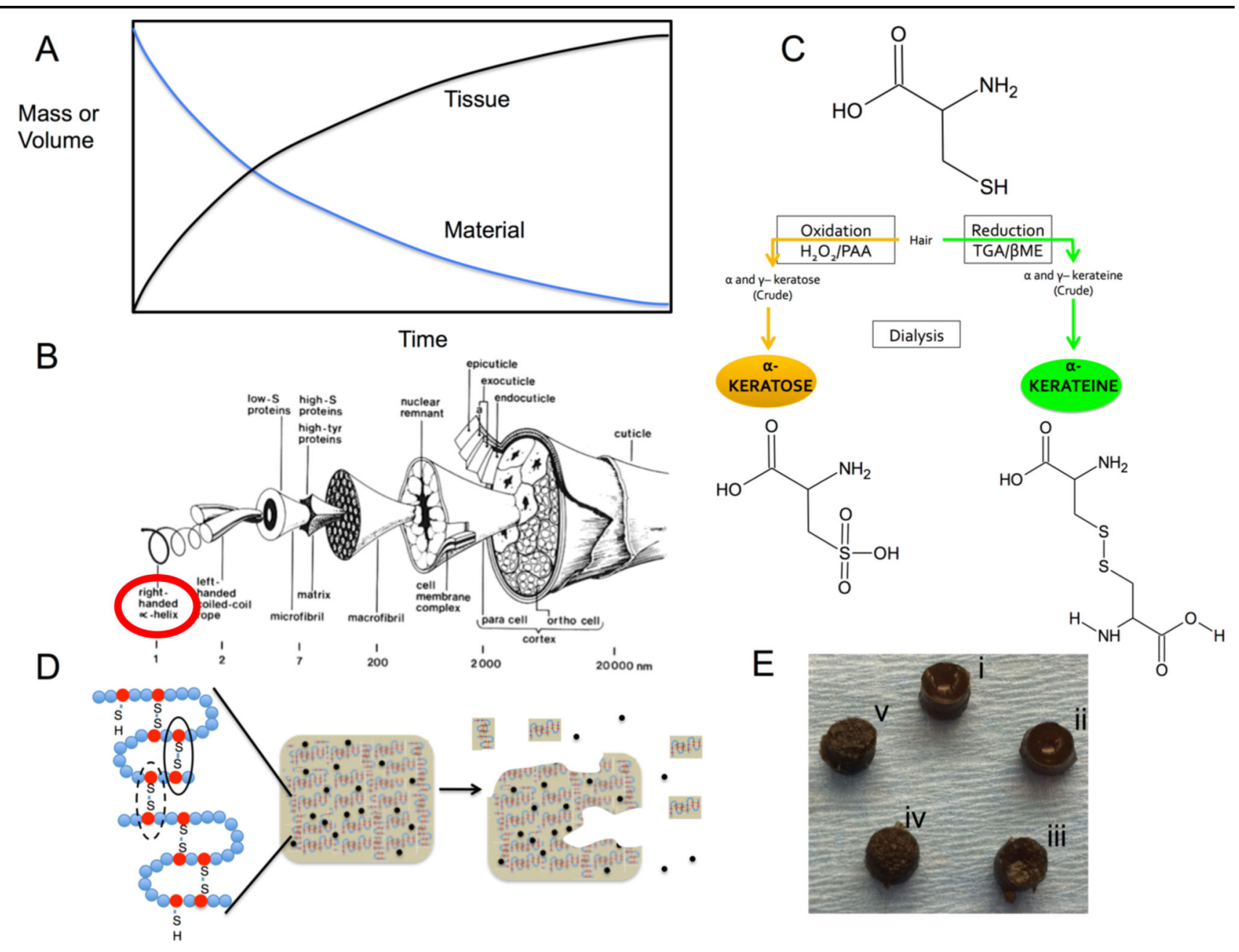

Figure 1.

(A) An idealized tissue engineering approach depicting tissue regeneration occurring in a manner inversely proportional to material erosion. (B) Structure of a wool fiber, similar to human hair as originally drawn by Fraser and Macrae (CSIRO Australia). Reprinted from Biomaterials v. 29(1), Sierpinski et al, "The use of keratin biomaterials derived from human hair for the promotion of rapid regeneration of peripheral nerves", pages 118-128, 2008 with permission from Elsevier. ${ }^{15}$ Alpha keratins (circled) were used in this study. (C) Schematic of cysteine residues in keratin following oxidative (left) or reductive (right) extraction and the resulting differences in disulfide crosslinking (black lines) and chain entanglement in hydrogels of keratose (left) and kerateine (right). (D) Approach to modulate disulfide crosslinking for control of material erosion and release of therapeutic agents (black circles). Reprinted from Acta Biomaterialia v. 23, Han et al., "Alkylation of human hair keratin for tunable hydrogel erosion and drug delivery in tissue engineering applications", pages 1189-1197 (graphical abstract), 2015 with permission from Elsevier. ${ }^{33}$ (E) Images of cylindrical form of each keratin hydrogel formulation (5 mm diameter): (i) KOS, (ii) 70:30 KOS:KTN, (iii) 50:50 KOS:KTN, (iv) 30:70 KOS:KTN, and (v) KTN. 

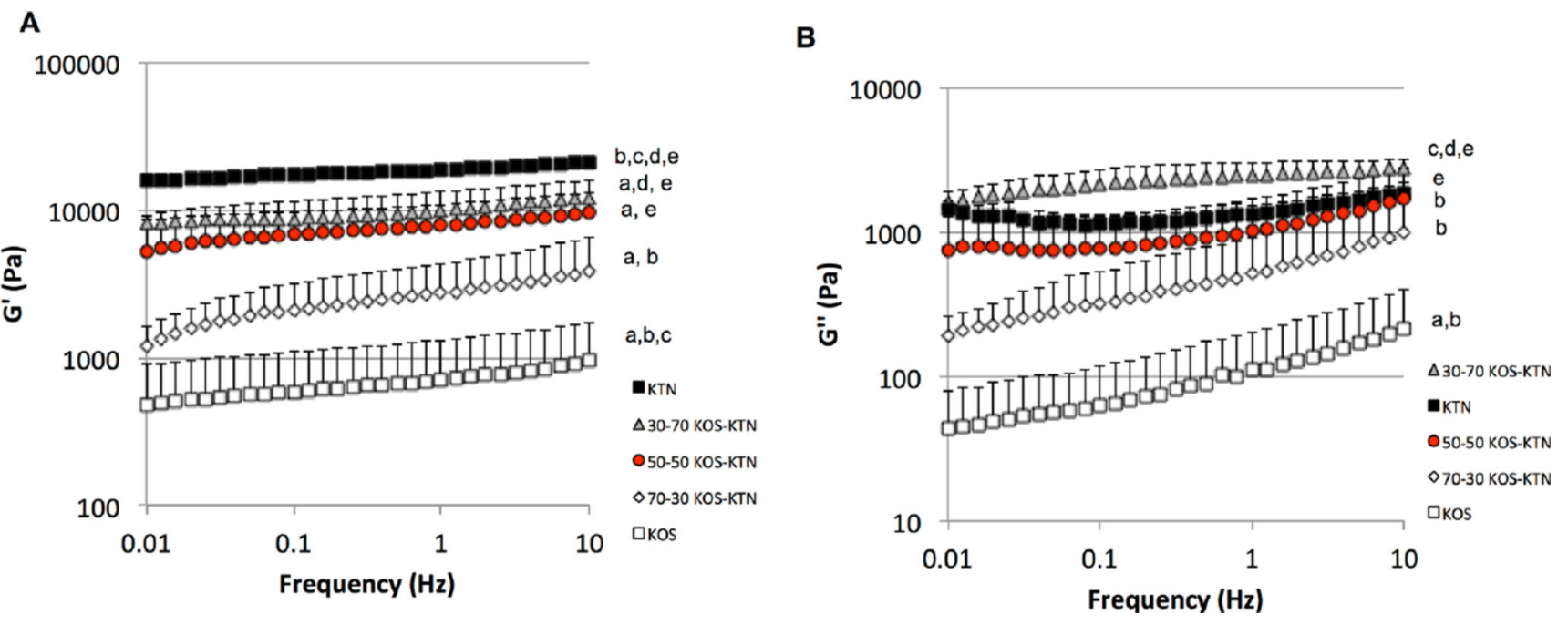

Figure 2.

Rheological data for each formulation. (A) G' (elastic modulus) and (B) G" (viscous modulus) for frequency sweep from .01 to $10 \mathrm{~Hz}$. Error bars indicate standard deviation and $\mathrm{n}=3$ for each formulation. The trend indicates increasing elastic modulus with increasing levels of disulfide crosslinking (increasing levels of KTN). For statistical comparisons (oneway ANOVA followed by Tukey's post hoc test): a indicates P < 0.05 vs. KTN; b indicates P $<0.05$ vs. 30:70 KOS:KTN; c indicates $\mathrm{P}<0.05$ vs. 50:50 KOS:KTN; d indicates $\mathrm{P}<0.05$ vs. 70:30 KOS:KTN; and e indicates $\mathrm{P}<0.05$ vs. KOS. 


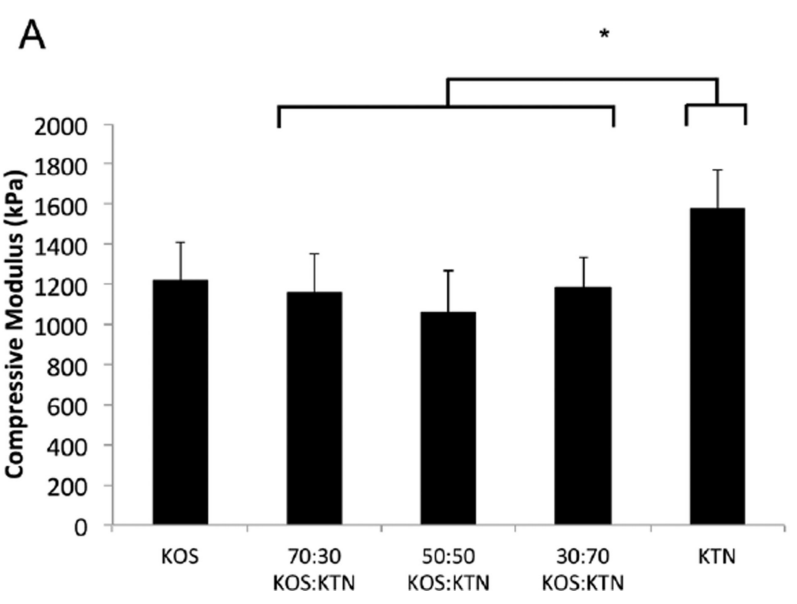

B

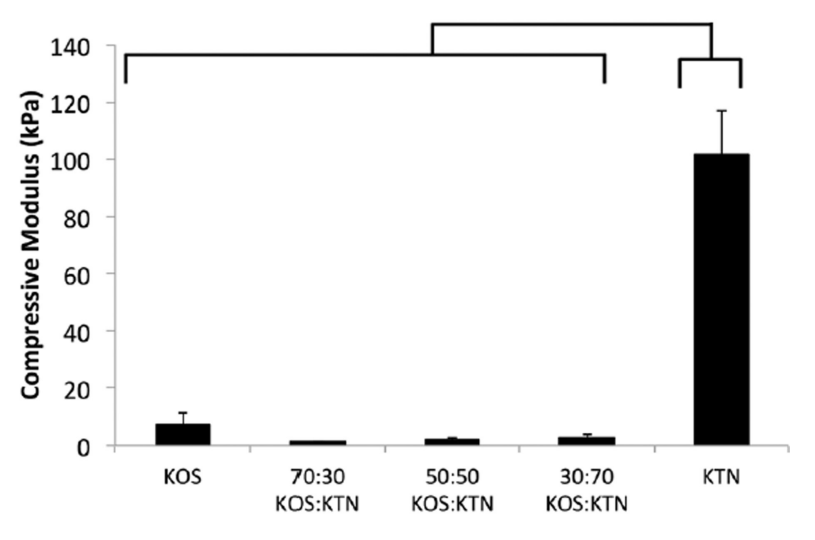

Figure 3.

Compressive moduli for each keratin formulation for (A) freeze-dried scaffolds and (B) hydrogels. Error bars indicate standard deviation and $\mathrm{n}=3$ for each formulation. * Indicates $\mathrm{P}<0.05$ vs. KTN as determined by Tukey's post-hoc test. 

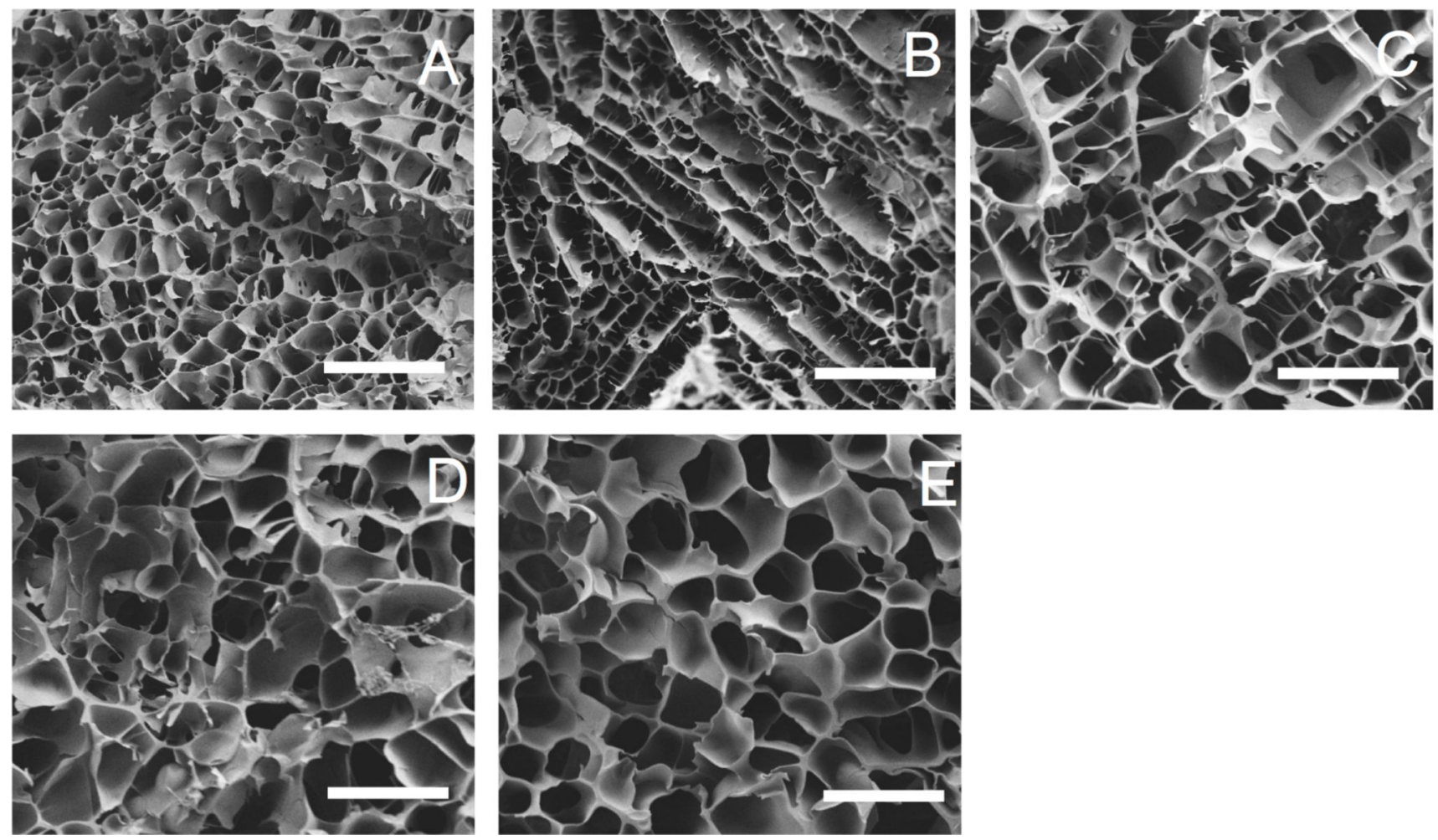

Figure 4.

Scanning electron micrographs of keratin gels. Each image is representative of the various formulations: (A) KOS (100:0 KOS:KTN) (B) 70:30 KOS:KTN. (C) 50:50 KOS:KTN. (D) 30:70 KOS: KTN. (E) KTN (0:100 KOS:KTN). Pore size and overall structure can be discerned. Images taken at 500X and 5kV. Scale bars represent $100 \mathrm{pm}$. 


\section{Day 0}
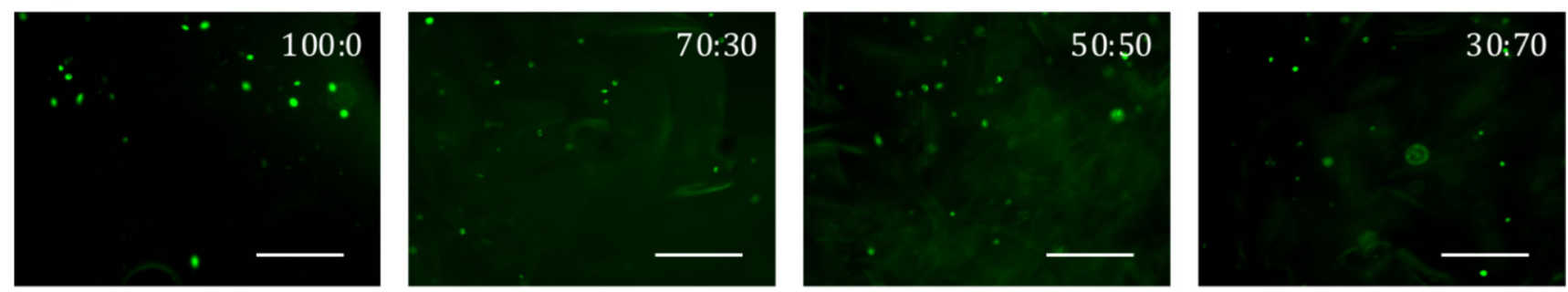

\section{Day 3}
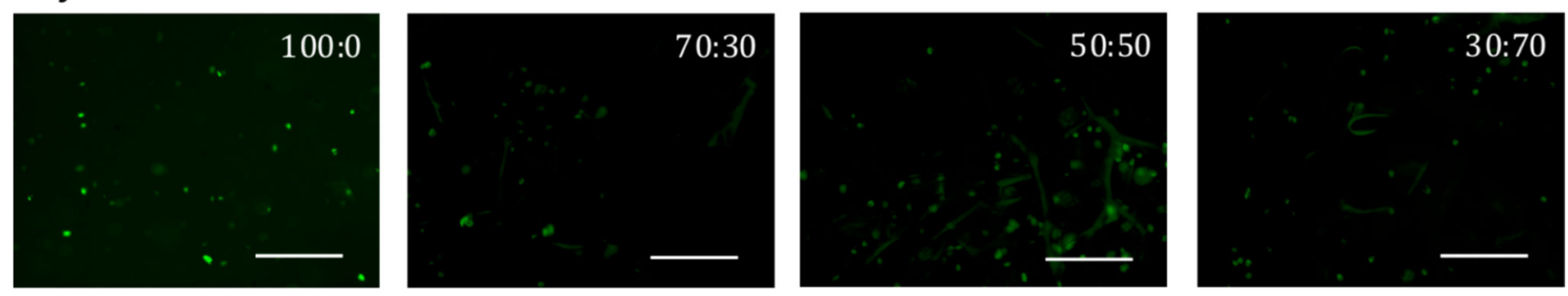

\section{Day 5}
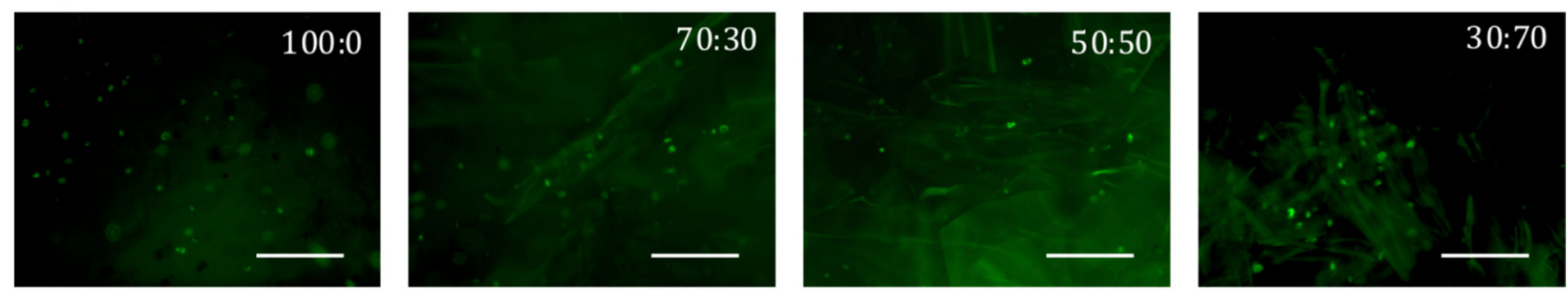

Day 7
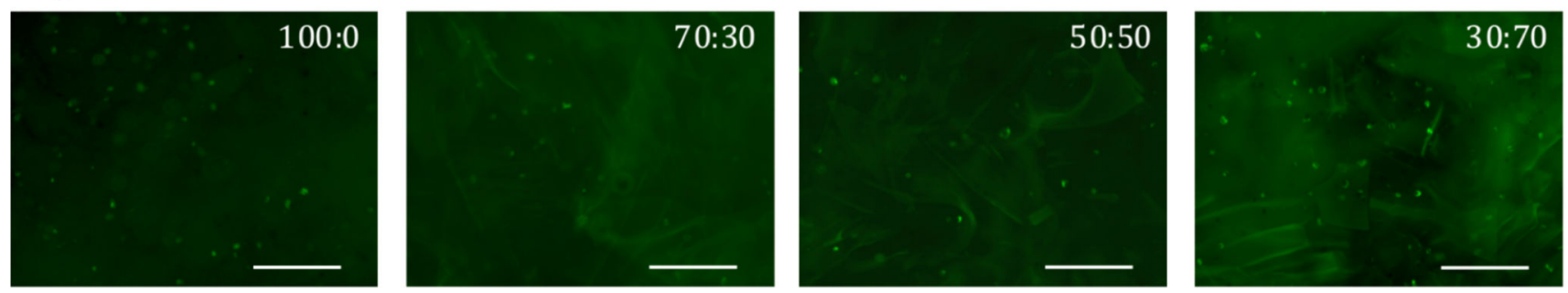

Figure 5.

Viability of MC3T3-E1 cells in keratin hydrogels immediately after formation (Day 0) or after 3, 5, or 7 days of incubation in the formulations indicated. Ratios indicate KOS:KTN ratios. 0:100 KOS:KTN $(100 \% \mathrm{KTN})$ is absent due to its inability to gel in the salts present in cell culture media. Cells stained green (calcein-AM) represent live cells. Images were chosen to be representative of the amount and distribution of cells in each formulation. Scale bar represents $250 \mu \mathrm{m}$. 

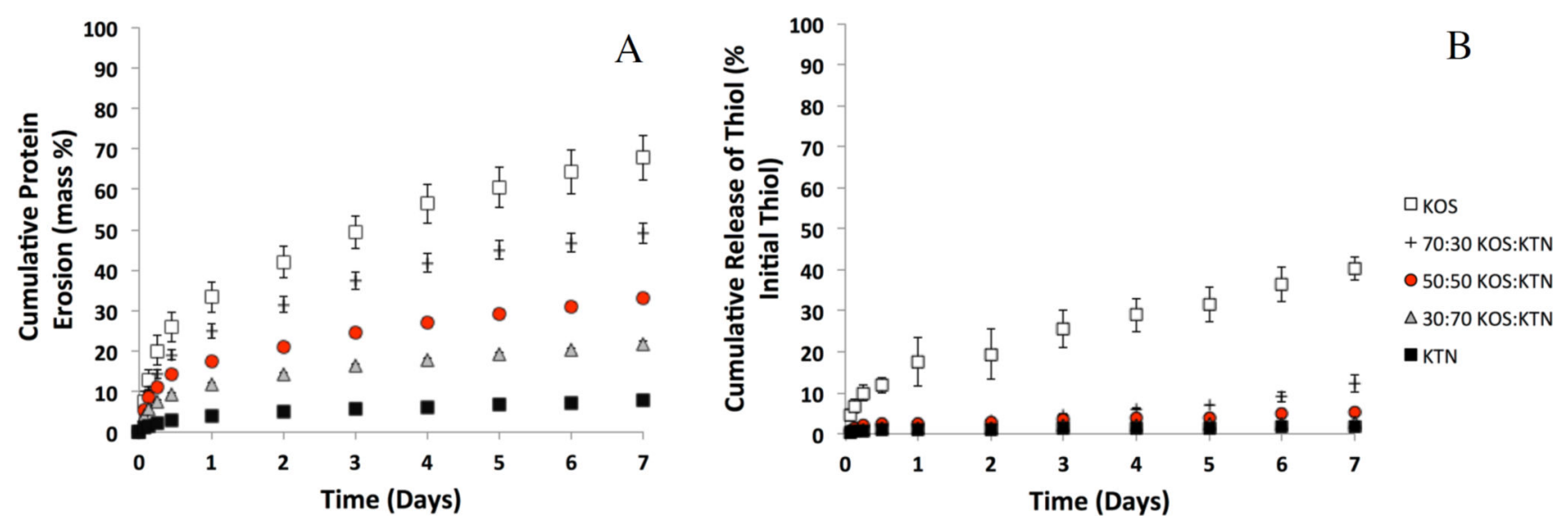

Figure 6.

(A) Cumulative erosion of keratin gel mass with time, demonstrating the relative differences in erosion rate by simply changing the KOS:KTN ratios. Data are shown as percentage of the total protein $(15 \mathrm{mg}$ ) for each hydrogel formulation. Error bars represent standard deviation and $\mathrm{n}=4$ for each formulation. Each formulation was significantly different than every other formulation by the $\sim 12$ hour time point. (B) Cumulative percent of thiol release with time. Data are shown as percentage of the total thiol content released based on the thiol content in gel starting materials (kerateine and keratose). Error bars represent standard error of the mean and $n=3$ for each formulation. 




Figure 7.

Release of rhIGF-1 from keratin gels with time. Each sample was loaded with $100 \mu \mathrm{g}$ of rIGF-1 per $\mathrm{mL}$ of keratin hydrogel. Each data point represents cumulative release as a percentage of initial rhIGF-1 loading. The rates of release can be seen to correlate with the rates of erosion seen in Figure 6. Error bars represent standard deviation and $n=4$ for each formulation. Each formulation was statistically different than every other formulation by the $\sim 12$ hour time point except that 30:70 and 50:50 KOS:KTN did not reach statistical significance until day 6. 


\section{Table 1}

Outline of keratin hydrogel formulations and thiol content

\begin{tabular}{|c|c|c|}
\hline Formulation & $\begin{array}{l}\text { Typical Preparation for a } \\
15 \% \text { w/v keratin hydrogel } \\
\text { using 1mL water (with or } \\
\text { without rhIGF-1) }\end{array}$ & $\begin{array}{l}\text { Thiol Content of Starting } \\
\text { Materials in a Typical } \\
\text { 1mL preparation }\end{array}$ \\
\hline 100:0 KOS:KTN & $\begin{array}{l}\text { KOS: } 150 \mathrm{mg} \\
\text { KTN: } 0 \mathrm{mg}\end{array}$ & $\begin{array}{l}\text { KOS: } 1.91 \pm 0.23 \mu \mathrm{mol} \\
\text { KTN: } 0 \\
\text { Total Thiol: } 1.91 \pm 0.23 \mu \mathrm{mol}\end{array}$ \\
\hline 70:30 KOS:KTN & $\begin{array}{l}\text { KOS: } 105 \mathrm{mg} \\
\text { KTN: } 45 \mathrm{mg}\end{array}$ & $\begin{array}{l}\text { KOS: } 1.33 \pm 0.16 \mu \mathrm{mol} \\
\text { KTN: } 6.26 \pm 0.63 \text { Total } \\
\text { Total Thiol: } 7.69 \pm 0.79\end{array}$ \\
\hline 50:50 KOS:KTN & $\begin{array}{l}\text { KOS: } 75 \mathrm{mg} \\
\text { KTN: } 75 \mathrm{mg}\end{array}$ & $\begin{array}{l}\text { KOS: } 0.95 \pm 0.11 \mu \mathrm{mol} \\
\text { KTN: } 10.4 \pm 1.05 \mu \mathrm{mol} \\
\text { Total Thiol: } 11.4 \pm 1.16 \mu \mathrm{mol}\end{array}$ \\
\hline 30:70 KOS:KTN & $\begin{array}{l}\text { KOS: } 45 \mathrm{mg} \\
\text { KTN: } 105 \mathrm{mg}\end{array}$ & $\begin{array}{l}\text { KOS: } 0.57 \pm 0.07 \mu \mathrm{mol} \\
\text { KTN: } 14.6 \pm 1.47 \\
\text { Total Thiol: } 15.2 \pm 1.54 \mu \mathrm{mol}\end{array}$ \\
\hline 0:100 KOS:KTN & $\begin{array}{l}\text { KOS: } 0 \mathrm{mg} \\
\text { KTN: } 150 \mathrm{mg}\end{array}$ & $\begin{array}{l}\text { KOS: } 0 \\
\text { KTN: } 20.9 \pm 2.1 \mu \mathrm{mol} \\
\text { Total Thiol: } 20.9 \pm 2.1 \mu \mathrm{mol}\end{array}$ \\
\hline
\end{tabular}

